\title{
MAGNETISCHE BEOBACHTUNGEN IN SEDDIN WÄHREND DES KOMETENDURCHGANGS, 19. Mai, 1910.
}

\section{VoN A. NIPPOLDT.}

Gestatten Sie mir, mitzuteilen, dass wir im Observatorium $z \mathbf{u}$ Seddin, von Mai I6, oh a. m. M. Gr. Z., bis Mai $2 \mathrm{r}$, Mitternacht, 8stündig, schnell laufend die Komponenten $X, Y, Z$ registriert haben. Die Emptindlichkeit betrug bei allen dreien $2 \gamma$ auf den $\mathrm{mm}$. Von Mai 20, $5^{\text {h }}$ a. $\mathrm{m}$. bis $\mathrm{I}^{\mathrm{h}}$ p. m. und Mai $2 \mathrm{I}$, $\mathrm{I}^{\mathrm{h}}$ P. $\mathrm{m}$. bis Mn war der Lichtpunkt für $Z$ unwirksam geworden; es bot $Z$ aber in dieser Zeit, wie Potsdam zeigt, nichts von besonderem Interesse. Irgendein eigentïmliches, nur bei schneller Registrierung erkennbares Phaenomen, das für einen Kometeneinfluss spräche, lassen die Kurven nicht erkennen.

Nach den ïblichen Registrierungen zu Potsdam, war am I7. Mai eine kleine, aber ausgeprägte Störung, die sich von der ruhigen Umgebung scharf abhob. Die Eintrittszeiten ergeben sich am besten aus $Z$ und zwar zu $3^{\text {h }}$ I8.3 ${ }^{\mathrm{m}}$, M. Gr. Z., p. m., das Ende etwa $4^{\mathrm{h}} 25^{\mathrm{m}}$, Amplitude $7.7 \gamma$; in $H, 60 \gamma$; in $D$ ist kein so scharfer Unterschied gegen die Umgebung vorhanden. Diese Störung hat etwas Seltenes im Aussehen, da sie mit recht lebhaften Schwankungen auf kleinen Raum zusammengedrängt ist.

I $\mathrm{r}^{\mathrm{h}}$ a. ml. am I8. Mai setzt eine mässige, aber bis in den r9. Mai sich hinziehende Störung ein. Mai I9, Io $^{h}$ a. m. bis $I \frac{1}{2^{h}}$ p. m., ist in das Ganze wieder eine Sonderstörung eingesetzt. Für die Hauptstörung tritt der Maximalwert um $4^{\text {h }} \mathrm{o}^{\mathrm{m}} \mathrm{p}$. m. ein; hier nach $Z$ Potsdam der Ursache am nächsten.

Das zeitliche Zusammenfallen der Störung mit dem Durchgang durch den Schweif beweist noch nichts über die ursächliche Verbindung. Der Durchgang dauerte nicht so lange, wie die Störung. Die magnetische Störung vom I8./ I9. hat einen Vorläufer, wie sehr viele Störungen solaren Ursprungs. Die Leuchtkraft des Schweifes war so gering, dass er nur in den Tropen und Subtropen in grösserer Ausdehnung zu sehen war. Dies spricht ïberhaupt fïr eine geringe Energie und somit auch für recht schwache ionisierende Kräfte in den vom letzten sichtbaren Ende noch weit enfernten Luftregionen.

Das Potsdamer Material steht auf Anfrage den Fachkollegen gerne zur Verfügung, mit allen zu seiner Verwertung nötigen Daten. Die Störung wird ausserdem in Kopien allgemein verbreitet werden. 